\title{
3 Research Square \\ COVID-19: Are you ready to seek psychological help during home quarantine?
}

\section{Hui Zhang}

Harbin Medical University

\section{Hong Su}

Harbin Medical University (Daqing)

\section{Dongxue Wang}

Harbin Medical University (Daqing)

\section{Lining Wang}

Harbin Medical University (Daqing)

\section{Yunjiang Cai}

Harbin Medical University (Daqing)

\section{Yuqiu Zhou ( $\sim$ hlxzyq@126.com )}

School of Nursing, Harbin Medical University (Daqing) https://orcid.org/0000-0002-3156-5245

\section{Research article}

Keywords: COVID-19, help-seeking, mental health, psychological distress

Posted Date: April 24th, 2020

DOI: https://doi.org/10.21203/rs.3.rs-21747/v1

License: (c) (1) This work is licensed under a Creative Commons Attribution 4.0 International License.

Read Full License 


\section{Abstract}

Background: Since December 2019, an increasing number of cases named Corona Virus Disease 2019 (COVID-19) have been identified in Wuhan, China. It has widely and rapidly spread in China and several other countries. The public experienced mental health problems during home quarantine.

Methods $\triangle$ From Feb 17 to 20,2020 , a questionnaire star survey was used to evaluate the psychological distress / psychological help-seeking attitudes and behavior of 3,248 people over 18 years old who were quarantined at home, all the subjects filled out the questionnaires, including general information questionnaire, Kessler Psychological Distress Scale (K-10),Attitudes Toward Seeking Mental Health and Psychological help-seeking behavior items.

Results:3,248 individuals were enrolled, and the score of psychological distress scale was $15 \cdot 93 \pm 6 \cdot 99$, the score of psychological help seeking was $82.34 \pm 13 \cdot 04$. Among the socio-economic factors, age was positively associated with the psychological distress $(t=5 \cdot 60, P<0 \cdot 05)$ and attitudes toward seeking mental health( $t=-3 \cdot 380, P<0 \cdot 05)$; the level of income were negatively associated with psychological distress $(\mathrm{t}=-2 \cdot 609, \mathrm{P}<0 \cdot 05)$ and attitudes toward seeking mental health $(\mathrm{t}=-2 \cdot 762, \mathrm{P}<0 \cdot 05)$; occupation were negatively associated with the level of psychological distress $(t=-2 \cdot 842, P<0 \cdot 05)$; gender and the level of education were positively associated with the level of attitudes toward seeking mental health $(t=6 \cdot 355, P<0 \cdot 05, t=3 \cdot 780, P<0.05)$; marital status were negatively associated with the level of attitudes toward seeking mental health $(\mathrm{t}=-3 \cdot 455, \mathrm{P}<0 \cdot 05)$.

Conclusions: Widowed, rural residents, people with low level of education and economic income should be the focus of COVID-19's mental health maintenance, and making good use of media and internet tools to strengthen publicity is one of the key points of current prevention and control.

\section{Background}

A novel coronavirus (2019-nCoV) has been identified as originating in Wuhan, Hubei Province, China. It has widely and rapidly spread in China and several other countries, causing an outbreak of acute infectious pneumonia. January 30, 2020, the World Health Organization (WHO) declared this disease a "Public Health Emergency of International Concern." Fear of the unknown raises anxiety level in healthy individuals as well as those with preexisting mental health. In order to reduce human-to-human transmission, the governments, health administrative departments and medical health institutions have adopted a series of prevention and control measures in accordance with the law, such as isolation and treatment of patients, isolation of close contacts for medical observation, home isolation of ordinary people, and so on. The public is required to be quarantined at home, delay in returning to work and school, which have affected the public normal life and have resulted in different types of psychological distress such as anxiety, distress, irritability, and panic[1].

Strict quarantine measures, the spread of the epidemic, and worries about themselves and their families have a certain impact on the mood of people who are quarantined at home. With the rapid rise in the 
number of infections, the public has become emotionally unstable and blindly following the crowd (such as looting for daily necessities). If psychological counseling is not carried out in time, it will not only bring serious consequences to individual mental health, but also affect social order. Fast transmission of the virus between people hinders traditional face-to-face psychological survey. By contrast, provision of online mental health assessment is safe. In this study, WeChat was used to investigate the psychological distress, attitudes Toward Seeking Mental Health Services and behavior characteristics of the public during the outbreak of COVID-19, and to analyze the factors affecting public psychological distress and psychological desire for help seeking, so as to provide support and basis for carrying out psychological assistance and psychological intervention for the public under public health emergencies.

\section{Methods}

\section{Participants}

The subjects are adult residents over 18 years old in The People's Republic of China. The awareness rate is $25 \%$, and the design effect is 2 . The recovery rate of the questionnaire is $90 \%$, and the minimum sample size is 2,667 according to the current situation research formula.

\section{Measures}

This study was a cross-sectional study carried out by researchers from Harbin Medical University, based on WeChat to fill in the questionnaire online (questionnaire Star, https://www.wjx.cn), the survey tools used are as follows:

The general information questionnaire was used to assess the demographic information, including age, gender, family income, degree of education, Occupation, marital status, Current province, city and place of residence and if there are confirmed COVID-19 cases around. The degree of education was divided into elementary school or below, junior school, senior school, college graduate and master or above. Marital status was divided into single, married, divorced and widowed. Household monthly income was categorized as "<2000 RMB", "2000 3999 RMB","4000 5999 RMB" or ">6000 RMB "; Occupation was divided into unemployed, civil servants, medical staff, teacher, student, farmer and so on .

Kessler Psychological Distress Scale(K-10) was used to assess personal psychological distress[2], which was developed by Kessler. The content includes the frequency of non-specific mental health symptoms related to anxiety and stress in the past four weeks. The questionnaire consists of ten items, each item has five response categories ranging, the score ranges from 10 to 50 . The higher the score, the more serious the psychological disturbance. The questionnaire has been used in Chinese older men and demonstrated good reliability and validity, with Cronbach's alphas for the total scale of 0.89 [3]. The Cronbach's alphas was 0.957 in this study.

Attitudes Toward Seeking Mental Health was measured by Inventory of Attitudes Toward Seeking Mental Health Services (IASMHS)[4]. This questionnaire included three aspects: Psychological openness factor, 
Psychological help-seeking tendency factor and Don't care about social stigma, the questionnaire consists of 24 items, each item is scored from 1 to 5 , the higher the total score, the more positive the subjects' psychological help-seeking attitude, and vice versa. The questionnaire has been used in Chinese adults and demonstrated good reliability and validity, the Cronbach's alpha was $0 \cdot 788[5]$. The Cronbach's alphas was 0.882 in this study.

Psychological help-seeking behavior is compiled according to previous research literature: set four items according to the help-seeking object and help-seeking behavior after psychological distress, including: To solve or endure on one's own, asking friends and relatives for help, using network information to ask for help and asking a professional for help (Psychological assistance hotline, Psychological counseling institutions, etc.).

\section{Statistical analysis}

The counting data are expressed by frequency and percentage, the measurement data are expressed by mean \pm standard deviation. Two independent sample t-tests were used for comparison between the two groups, and one-way ANOVA was used for multi-group comparisons. Pearson's correlations for continuous variables and linear regression to investigate whether socio-demographic variables could predict psychological distress and attitudes toward seeking mental health. Data analysis was carried out using the statistical program package SPSS 22.0, and P-values equal or lower than 0.05 were considered statistically significant.

\section{Results}

\section{Characteristics of the study population}

A total of 3,248 people from 31 provinces, municipalities directly under the Central Government and autonomous regions were surveyed, covering Hong Kong and Taiwan. The top six provinces with the largest number of subjects are: Heilongjiang 1,213, Shandong 180, Henan 156, Hebei 154,134 in Zhejiang and 131 in Liaoning. The age of these respondents ranged from 18 to 82 years (mean=30.02 $\pm 12 \cdot 61$ ). 759 were male (23.4\%), 2,489 were female (76.6\%), 1626 were in cities $(50 \cdot 1 \%)$ and 1622 were in villages and towns (49.9\%).Marital status:1944 (59.9\%) were unmarried, 1,201 (37\%) were married, 75 were divorced, 28 were widowed, the level of education was predominantly high and university or above (2,855cases,87.9\%), the main occupations were students 1,451 (44.7\%), 611 (18.8\%) were medical staff, 291 were teachers, 266 were farmers, 154 were company occupations, etc, monthly income was mostly $>6000 \mathrm{RMB}$ and 2000®3999 RMB (1,849cases, 56.93\%).

\section{The current situation of public psychological distress and attitudes toward seeking mental health under the outbreak of COVID-19 at home quarantine}

3,248 individuals were enrolled, and the score of psychological distress scale was $15 \cdot 93 \pm 6 \cdot 99,1,257$ had psychological disturbance (the total score of $\mathrm{K}-10 \geq 16$ ), accounting for $38 \cdot 7 \%$, and 208 had serious 
psychological disturbance (the total score of $\mathrm{K}-10 \geq 30$ ), accounted for $6 \cdot 4 \% .2,016(62 \cdot 1 \%)$ never or rarely felt anxiety and panic, $1,034(31 \cdot 8 \%)$ sometimes felt anxiety and panic, and $1,034(6 \cdot 1 \%)$ often or always felt anxiety and panic.

The score of psychological help-seeking was $82 \cdot 34 \pm 13 \cdot 04$. The scores of psychological openness, helpseeking tendency and social stigma were $23 \cdot 6 \pm 6 \cdot 30,28 \cdot 72 \pm 6 \cdot 31$ and $28 \cdot 72 \pm 6 \cdot 31$ respectively. In this study, the low, medium and high psychological help groups were defined according to the dividing cut-off points of $25 \%$ and $75 \%$. The number of people seeking help with low psychology was 913 (IASMHS $\leq 72$ ) $(28 \cdot 1 \%)$, those with moderate psychology was $1,510(72<\mathrm{IASMHS}<92)(53 \cdot 5 \%)$, and those with high psychology was 825 (IASMHS $\geq 92)(25 \cdot 4 \%)$. According to the analysis of psychological help-seeking behavior, when they encountered psychological distress under the COVID-19 at home quarantine, 1,692 people $(52 \cdot 1 \%)$ turned to their relatives and friends for help, and 1,519 people (46.8\%) would solve and endure it by themselves, 1,070 people (32.9\%) sought help through Internet information, and only 954 people (29.4\%) sought help from professionals (psychological assistance hotline, psychological counseling institutions). The elderly are more likely to solve and endure by themselves, while young people are more willing to turn to their relatives and friends and the Internet for help. Psychological distress was negatively correlated with Attitudes Toward Seeking Mental Health Services $\ r=-0 \cdot 228$, $P<0 \cdot 001 \rrbracket$.

\section{Univariate analysis of public psychological distress and attitudes toward seeking mental health under the outbreak of COVID-19 at home quarantine}

Univariate analysis showed that there were significant differences in public psychological disturbance among different ages, marital status, education level and occupation $(P<0.05)$, but there were no significant difference in family income and place of residence $(P>0.05)$. There were significant differences in the scores of public psychological help-seeking among different gender, age, marital status, education level, occupation, average monthly family income and place of residence $(P<0.05)$ (Table1,Table2 ).

\section{The socio-economic factors predicted the level of psychological distress and attitudes toward seeking mental health}

As shown in Table 3 and 4, among the socio-economic factors, age were positively associated with the psychological distress and attitudes toward seeking mental health; the level of income were negatively associated with psychological distress and attitudes toward seeking mental health; occupation were negatively associated with the level of psychological distress; sex and the level of education were positively associated with the level of attitudes toward seeking mental health; marital status were negatively associated with the level of attitudes toward seeking mental health.

\section{Discussion}


The results of this study showed that in face of the outbreak of COVID-19 at home quarantine, 38.7\% had psychological distress, $6 \cdot 4 \%$ had serious psychological distress, and $37 \cdot 9 \%$ felt anxiety and panic. Fear and anxiety are the most common emotional problems in face of an epidemic. Due to concerns about viral infection, the consequences of pneumonia, such as isolation, death, and under the requirements of the prevention and control situation, the work intensity is high, the psychological pressure increases sharply, and the occurrence of fear, tension and fear, excessive and long-term psychological stress reaction will lead to the occurrence of stress disorder[6]. Excessive activation of the sympathetic nervous system needlessly consumes physiological resources, resulting in a decline in immunity and aggravation of pulmonary microvascular exudation, which makes it more difficult to resist the challenge of the current virus, but also reduces cognitive function and affects work efficiency.

This study showed that $45 \cdot 1 \%$ had psychological distress and serious psychological problems, but only $29 \cdot 4 \%$ of the people were willing to seek professional psychological assistance, $52 \cdot 1 \%$ were willing to turn to friends and relatives for help, and $46 \cdot 8 \%$ would solve and endure by themselves, and $32 \cdot 9 \%$ sought help by using Internet information. Home isolators with psychological problems have a low proportion of professional psychological help, and many people choose to endure and solve psychological problems on their own.

Psychological distress was negatively correlated with attitudes toward seeking mental health services, psychological help-seeking has the advantages of correct cognition, strong will, positive behavior and scientific way, and its mental health level is higher[7]. Therefore, scientific and effective psychological assistance is very important to the public who have psychological distress and bad mood during the epidemic isolated at home. Local governments, mental health centers and scientific research institutes of universities have established platforms and hotlines for psychological assistance and crisis intervention, but the utilization rate of the public is not high. People who are isolated at home are more likely to choose relatives and friends, self-solution or tolerance to alleviate their inner troubles, so it can be seen that the methods of mental health assessment, psychological problem identification, psychological adjustment and counseling are particularly important. The public's knowledge of mental health and the methods of psychological adjustment and intervention through the use of the Internet are also relatively limited, and the intervention means need to pay more attention to the public mental health training suitable for familypeer mutual assistance and self-help. So that more people can accumulate a certain amount of mental health knowledge and psychological intervention skills in daily life, so as to more effectively apply to psychological assistance and intervention under public health emergencies, reduce psychological stress reaction, reduce psychological distress, and promote psychological resilience and psychological growth after stress.

According to the univariate and multiple regression analysis, the psychological problems of people with advanced age, low income and low education level are more serious. The level of mental health gradually decreases with the increase of age, and the cognitive function of the elderly is declining with the increase of age, and the decrease of the ability to participate in social activities has a negative impact on mental health[8]. In the old age, the function of various organs began to decline, and the physical function of the 
elderly decreased. At the same time, the fatality rate of the elderly in the COVID-19 epidemic was high, which aggravated the psychological distress of the elderly. Low-income individuals have serious psychological problems, and they often take negative psychological help-seeking, which is consistent with the results of previous study[9].

People with good financial conditions have less pressure to live and seek medical treatment, have a high degree of social participation and pay more attention to emotional needs. Women have more positive professional psychological intention to ask for help than men, it may be due to the gender advantage of women, women are more willing to talk to people, while men are more reluctant to ask for help because of face concerns[10]. People with a higher level of education have less psychological problems and are more likely to take positive psychological help, which may be related to the fact that people with a higher level of education have more ways of entertainment and live a more fulfilling and richer life[11], and those with a high level of education have some common sense of psychology and can adjust the bad mood caused by the epidemic in time. A good marriage can reduce the risk of mental illness[12]. This study also draws a similar conclusion that marital status has a significant impact on the public's psychological helpseeking behavior, and widows are more likely to take negative psychological help-seeking, which may be related to their state of living alone and lacking family support. A sound family structure can provide sufficient support at the material and spiritual levels. Rural residents often take negative psychological help-seeking, which may be related to the lack of channels and frequency for rural people to accept mental health. Although mobile phones and other electronic media are widely used at present, the popularity of the Internet has not been reached in rural areas, areas with low educational level and economically backward areas. Therefore, the local community and the government should publicize COVID-19's basic knowledge through online lectures, WeChat message push and other diversified channels, and invite professional psychological experts to guide them to properly regulate their bad emotions. Raise people's awareness of COVID-19, at the same time provide free online psychological counseling and psychological counseling professionals, and provide psychological counseling and counseling conditions for individuals in rural areas and poor economic conditions. For those who are widowed or living alone, their relatives and friends should be urged to show their emotional care, and community workers should regularly consult their psychological status by telephone, try to meet the reasonable needs of life, and if there are psychological problems, conduct psychological counseling or psychotherapy referrals to ensure that psychological problems are solved in a timely manner.

As far as we known, there are some limitations need to be considered. First, the data were collected by the WeChat, people who didn't use WeChat or couldn't get the available Internet could not attend the survey. Second, the majority of the participants were female $(76.63 \%)$ and most were young people $(79.19 \%)$ in the present study. The distress of the elderly should be further surveyed because they were fragile during the home quarantined. Third, the dynamic change of psychological distress should be assessed in the future study.

\section{Conclusion}


The mental health of the widowed, rural residents, people with low level of education and economic income should be paid much attention during the COVID-19 epidemic, and making good use of media and Internet tools to strengthen publicity is one of the key points of current prevention and control.

\section{Abbreviations}

COVID-19:Corona Virus Disease 2019; RMB: Ren Minbi; K-10: Kessler Psychological Distress Scale; IASMHS: Attitudes Toward Seeking Mental Health was measured by Inventory of Attitudes Toward Seeking Mental Health Services; ANOVA: Analysis of variance.

\section{Declarations}

\section{Ethics approval and consent to participate}

This survey has been approved by the ethics committee of Harbin medical university. All participants provided written informed consent. The questionnaire was treated as confidential and anonymous.

\section{Consent to publish}

Not applicable.

\section{Availability of data and materials}

The datasets used and/or analyzed during this study are available from the corresponding author on reasonable request.

\section{Competing interests}

The authors declare that they have no competing interests.

\section{Funding}

This study was funded by National Natural Science Foundation of Republic of China (NSFC, N0.71603064). The funding was used to collected the data in this study.

\section{Authors' contributions}

$\mathrm{HZ}$ and HS contributed equally for this manuscript. They analyzed data and wrote the manuscript. DW contributed to the data collection and data analysis. LW contributed to the literature search, YC collected the data. YZ did the study design, data collection and data interpretation. All authors have read and approved the final version of the manuscript.

\section{Acknowledgements}

We would like to thank all participants for their contributions to this study. 


\section{References}

1. Xiang YT, Yang Y, Li W. Timely mental health care for the 2019 novel coronavirus outbreak is urgently needed. Publishing Lancet Psychiatry. https://www.thelancet.com/journals/lanpsy/article/PIIS22150366(20)30046-8/fulltext. Accessed Mar 12,2020.

2. Kessler RC, Andrew G, Colpe LJ. Short screening scales to monitor population prevalence and trends non-specific psychological distress. Psychol Med,2002; 32(6):959-76.

3. Zhou CC, Chu J, Wang T. Evaluation of reliability and validity of Kessler10 Chinese version of Mini Mental status rating scale. Chinese Journal of Clinical Psychology,2008; 16(6):627-9.

4. Mackenzie CS, Knox VJ, Gekoski WL. An Adaptation and Extension of the Attitudes Toward Seeking Professional Psychological Help Scale. J Appl Soc Psychol,2003; 34(11):2410-35.

5. Zhou XR, STUDART C, Shi QJ. Negative mentality, coping style and attitude of seeking professional psychological help of medical college students. Chinese Journal of Mental Health; 2010; 24(10):7905.

6. Goenjian AK, Steinberg AM, Najarian LM. Prospective study of posttraumatic stress, anxiety, and depressive reactions after earthquake and political violence. Am J Psychiatry,2000; 157( 6) : 911-6.

7. Chen MF. Study on the relationship between psychological help-seeking, coping style and mental health status of nursing undergraduates. Dissertation, Tianjin Medical University;2016.

8. Luo S, Luo L, Zhang J. Meta Analysis of the influencing factors of Mental Health of the elderly in China. Chinese Journal of Gerontology,2017; 3(24):6194-6.

9. Liao ZH, Wang WQ, Ding LJ . Multi-level Model and its Application in the study of influencing factors of Psychological Disorder in Community population. Chinese health statistics,2013; 4:525-8.

10. Liu CY. Professional psychological help-seeking status of adolescents and its influencing factors and mechanism. Dissertation, Beijing normal University;2010.

11. Shi J, Zhang Y, Liu F. Associations of Educational Attainment, Occupation, Social Class and Major Depressive Disorder among Han Chinese Women. PloS one,2014; 9(1):e86674. https://doi.org/10.1371/journal.pone.0086674

12. Yuan M, Wang N, Yuan DY.Study on the influence of different marital status on health status. Chinese Journal of traditional Chinese Medicine,2010; 29(7):1535-1537.

\section{Tables}

Table 1 Univariate analysis of public psychological distress under the outbreak of COVID-19 at home quarantine 


\begin{tabular}{|c|c|c|c|c|c|}
\hline Variable & & $N(\%)$ & $\begin{array}{l}\text { Psychological } \\
\text { distress }\end{array}$ & $t / F$ & $\mathbf{P}$ \\
\hline \multirow[t]{2}{*}{ Gender } & Male & 759₫23.37ه & $16.01 \pm 7.24$ & $t=0.52$ & 0.062 \\
\hline & Female & $\begin{array}{l}2489 \\
\square 76.63 \rrbracket\end{array}$ & $15.85 \pm 6.88$ & & \\
\hline \multirow[t]{3}{*}{ Age } & The elderly & $30(0.92)$ & $21.53 \pm 10.49$ & $F=14.93$ & 0.000 \\
\hline & Middle-aged people & 646(19.88) & $16.66 \pm 6.85$ & & \\
\hline & Young people & $2572(79.19)$ & $15.68 \pm 6.94$ & & \\
\hline \multirow[t]{4}{*}{ Marital status } & Married & $\begin{array}{l}1201 \\
\otimes 36.98 \rrbracket\end{array}$ & $16.68 \pm 6.78$ & $F=18.58$ & 0.000 \\
\hline & Never Married & $\begin{array}{l}1944 \\
\text { \59.85】 }\end{array}$ & $15.31 \pm 6.93$ & & \\
\hline & Divorced & $75 \rrbracket 2.31 \rrbracket$ & $17.82 \pm 7.04$ & & \\
\hline & Windowed & $28 \rrbracket 0.86 \rrbracket$ & $21.85 \pm 12.12$ & & \\
\hline \multirow[t]{5}{*}{ Education } & $\begin{array}{l}\text { Primary school or } \\
\text { below }\end{array}$ & $174 \llbracket 5.36 \rrbracket$ & $18.72 \pm 8.01$ & $F=9.30$ & 0.000 \\
\hline & Secondary school & $219 \llbracket 6.62 \rrbracket$ & $15.99 \pm 6.49$ & & \\
\hline & High school & 499ه15.36ه & $15.07 \pm 6.20$ & & \\
\hline & $\begin{array}{l}\text { College/bachelor } \\
\text { degree }\end{array}$ & $\begin{array}{l}2043 \\
\square 62.96 \rrbracket\end{array}$ & $15.83 \pm 7.10$ & & \\
\hline & Graduate student & $313 \llbracket 9.64 \rrbracket$ & $16.35 \pm 6.86$ & & \\
\hline \multirow[t]{9}{*}{ Occupation } & No job & 126ه3.88区 & $12.02 \pm 8.44$ & $F=9.66$ & 0.000 \\
\hline & farmer & $266 \rrbracket 8.19 \rrbracket$ & $17.70 \pm 7.51$ & & \\
\hline & Medical staff & $611 \otimes 9.58 \rrbracket$ & $17.14 \pm 7.34$ & & \\
\hline & Civil servants & $41 \otimes 1.26 \rrbracket$ & $17.02 \pm 7.60$ & & \\
\hline & Service trade & $79 \rrbracket 2.43 \rrbracket$ & $16.64 \pm 6.87$ & & \\
\hline & Clerk & $154 \llbracket 4.74 \rrbracket$ & $16.28 \pm 6.91$ & & \\
\hline & Individual & $87 \rrbracket 2.68 \rrbracket$ & $15.40 \pm 5.93$ & & \\
\hline & Teacher & $291 \rrbracket 8.96 \rrbracket$ & $15.40 \pm 5.90$ & & \\
\hline & Student & $\begin{array}{l}1451 \\
\otimes 44.67 \rrbracket\end{array}$ & $14.88 \pm 6.69$ & & \\
\hline $\begin{array}{l}\text { Monthly household } \\
\text { income }\end{array}$ & $<2000$ & $758 \llbracket 23.34 \rrbracket$ & $16.42 \pm 7.57$ & 2.40 & 0.066 \\
\hline
\end{tabular}




\begin{tabular}{|c|c|c|c|c|c|}
\hline & 2000-3999 & $846 \rrbracket 26.05 \rrbracket$ & $15.48 \pm 6.87$ & & \\
\hline & 4000-5999 & 641ه19.74】 & $15.87 \pm 6.85$ & & \\
\hline & $>6000$ & $\begin{array}{l}1003 \\
\rrbracket 30.88 \rrbracket\end{array}$ & $15.96 \pm 6.71$ & & \\
\hline \multirow[t]{3}{*}{ Home place } & City & 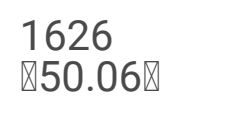 & $16.12 \pm 6.90$ & 1.59 & 0.205 \\
\hline & Small towns & 406ه12.5区 & $15.49 \pm 6.98$ & & \\
\hline & Rural area & $\begin{array}{l}1216 \\
\otimes 37.44 \rrbracket\end{array}$ & $15.81 \pm 7.12$ & & \\
\hline
\end{tabular}

Table 2 Univariate Analysis of public attitudes toward seeking mental health under the outbreak of COVID-19 at home quarantine 


\begin{tabular}{|c|c|c|c|c|c|}
\hline Variable & & $N(\%)$ & $\begin{array}{l}\text { Attitudes Toward Seeking } \\
\text { Mental Health Services }\end{array}$ & $t / F$ & $\mathbf{P}$ \\
\hline \multirow[t]{2}{*}{ Gender } & Male & 759®23.37区 & $79.16 \pm 13.53$ & $\mathrm{~T}=5.29$ & 0.022 \\
\hline & Female & $\begin{array}{l}2489 \\
\otimes 76.63 \rrbracket\end{array}$ & $83.32 \pm 12.73$ & & \\
\hline \multirow[t]{3}{*}{ Age } & The elderly & $30(0.92)$ & $76.00 \pm 17.21$ & $F=9.48$ & 0.000 \\
\hline & $\begin{array}{l}\text { Middle-aged } \\
\text { people }\end{array}$ & 646(19.89) & $80.84 \pm 13.57$ & & \\
\hline & Young people & 2572(79.19) & $82.79 \pm 12.80$ & & \\
\hline \multirow[t]{4}{*}{ Marital status } & Married & 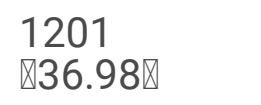 & $82.23 \pm 13.42$ & $F=5.67$ & 0.001 \\
\hline & Never Married & 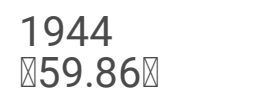 & $82.66 \pm 12.64$ & & \\
\hline & Divorced & $75 \bowtie 2.31 \rrbracket$ & $78.95 \pm 13.44$ & & \\
\hline & windowed & 28囚0.86》 & $74.32 \pm 18.26$ & & \\
\hline \multirow[t]{5}{*}{ Education } & $\begin{array}{l}\text { Primary school } \\
\text { or below }\end{array}$ & $174 \rrbracket 5.36 \rrbracket$ & $78.29 \pm 15.66$ & $F=16.47$ & 0.000 \\
\hline & $\begin{array}{l}\text { Secondary } \\
\text { school }\end{array}$ & $219 \llbracket 6.74 \rrbracket$ & $78.73 \pm 14.77$ & & \\
\hline & High school & 499ه15.36ه & $81.99 \pm 13.02$ & & \\
\hline & $\begin{array}{l}\text { College/ } \\
\text { bachelor } \\
\text { degree }\end{array}$ & $\begin{array}{l}2043 \\
\square 62.90 \rrbracket\end{array}$ & $82.55 \pm 12.64$ & & \\
\hline & $\begin{array}{l}\text { Graduate } \\
\text { student }\end{array}$ & $313 \varangle 9.64 \rrbracket$ & $86.39 \pm 11.33$ & & \\
\hline \multirow[t]{9}{*}{ Occupation } & No job & 126『3.88ه & $78.20 \pm 13.23$ & $F=6.76$ & 0.000 \\
\hline & Farmer & 266ه8.19》 & $78.83 \pm 16.56$ & & \\
\hline & Medical staff & $611 \otimes 18.81 \rrbracket$ & $93.18 \pm 12.65$ & & \\
\hline & Civil servants & $41 \otimes 1.26 \rrbracket$ & $82.93 \pm 12.60$ & & \\
\hline & Service trade & $79 \bowtie 2.43 \rrbracket$ & $78.99 \pm 11.91$ & & \\
\hline & Clerk & $154 \llbracket 4.74 \rrbracket$ & $82.38 \pm 12.59$ & & \\
\hline & Individual & 87囚2.68凹 & $81.00 \pm 14.14$ & & \\
\hline & Teacher & $291 \rrbracket 8.96 \rrbracket$ & $86.09 \pm 11.52$ & & \\
\hline & Student & 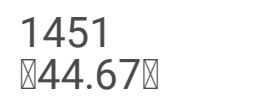 & $82.53 \pm 12.47$ & & \\
\hline
\end{tabular}




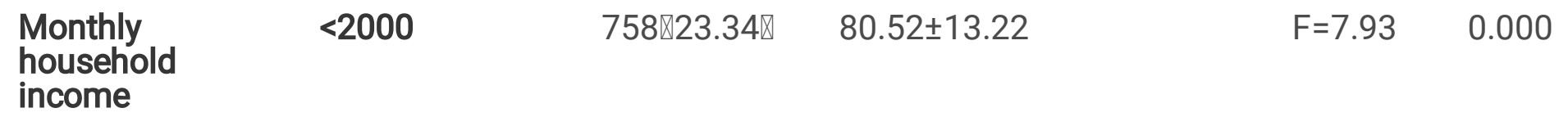

\begin{tabular}{|c|c|c|c|c|c|}
\hline & 2000-3999 & 846囚26.05】 & $82.91 \pm 13.18$ & & \\
\hline & 4000-5999 & 641ه19.74】 & $83.18 \pm 13.23$ & & \\
\hline & $>6000$ & $\begin{array}{l}1003 \\
\varangle 30.88 \rrbracket\end{array}$ & $83.33 \pm 12.51$ & & \\
\hline \multirow[t]{3}{*}{ Home place } & City & 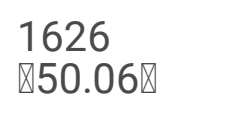 & $83.24 \pm 12.33$ & $F=7.78$ & 0.000 \\
\hline & Small towns & $406 \rrbracket 12.5 \rrbracket$ & $81.46 \pm 11.65$ & & \\
\hline & Rural area & 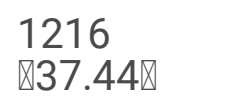 & $81.44 \pm 14.26$ & & \\
\hline
\end{tabular}

Table 3 The socio-economic factors predicted the level of psychological distress

\begin{tabular}{llllll} 
Variable & B & SE & Beta & t & P \\
\hline Age & .068 & .012 & .123 & 5.600 & .000 \\
\hline Gender & .043 & .298 & .003 & .145 & .884 \\
\hline Marital status & .371 & .254 & .030 & 1.462 & .144 \\
\hline Education & -.121 & .158 & -.016 & -.762 & .446 \\
\hline Occupation & -.176 & .062 & -.052 & -2.842 & .005 \\
\hline Monthly household income & -.346 & .133 & -.057 & -2.609 & .009 \\
\hline Home place & -.204 & .169 & -.027 & -1.203 & .229
\end{tabular}

Table 4 The socio-economic factors predicted the level of attitudes toward seeking mental health 


\begin{tabular}{llllll} 
Variable & B & SE & Beta & $\mathbf{t}$ & P \\
\hline Age & -.076 & .022 & -.074 & -3.380 & .001 \\
\hline Gender & 3.481 & .549 & .113 & 6.335 & .000 \\
\hline Marital status & -1.617 & .468 & -.070 & -3.455 & .001 \\
\hline Education & 1.105 & .292 & .079 & 3.780 & .000 \\
\hline Occupation & .126 & .115 & .020 & 1.100 & .271 \\
\hline Monthly household income & -.676 & .245 & -.060 & -2.762 & .006 \\
\hline Home place & .075 & .313 & .005 & .239 & .811
\end{tabular}

\section{Supplementary Files}

This is a list of supplementary files associated with this preprint. Click to download.

- dataset.sav 